\title{
Automatic face recording system based on quick response code using multicam
}

\author{
Julham$^{1}$, Muharman Lubis ${ }^{2}$, Arif Ridho Lubis ${ }^{1}$, Al-Khowarizmi ${ }^{3}$, Idham Kamil ${ }^{4}$ \\ ${ }^{1}$ Department of Computer Engineering and Informatics, Politeknik Negeri Medan, Medan, Sumatera Utara, Indonesia \\ ${ }^{2}$ School of Industrial Engineering, Telkom University, Bandung, Jawa Barat, Indonesia \\ ${ }^{3}$ Department of Information Technology, Universitas Muhammadiyah Sumatera Utara, Medan, Sumatera Utara, Indonesia \\ ${ }^{4}$ Department of Mechanical Engineering, Politeknik Negeri Medan, Medan, Sumatera Utara, Indonesia
}

\begin{tabular}{l} 
Article Info \\
\hline Article history: \\
Received May 10, 2021 \\
Revised Dec 20, 2021 \\
Accepted Jan 4, 2022 \\
\hline
\end{tabular}

Keywords:

Digital camera

QR code

Server

Webcam

\begin{abstract}
This research mainly talks about the use of quick response (QR) code reader in automating of recording the users' face. The applied QR code reader system is a dynamic type, which can be modified as required, such as adding a database, functioning to store or retrieve information in the QR code image. Since the QR code image is randomly based on its information, a QR code generator is required to display the image and store the information. While the face recorder uses a dataset available in the OpenCV library. Thus, only the registered $\mathrm{QR}$ code image can be used to record the user's face. To be able to work, the QR code reader should be 10 to $55 \mathrm{~cm}$ from the QR code image.
\end{abstract}

This is an open access article under the CC BY-SA license.

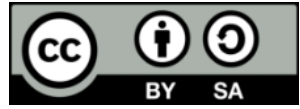

\section{Corresponding Author:}

Julham

Department of Computer Engineering and Informatics, Politeknik Negeri Medan

Jl. Almamater No.1, Padang Bulan, Kec. Medan Baru, Kota Medan, Sumatera Utara 20155, Indonesia

Email: julham76@gmail.com

\section{INTRODUCTION}

The use of quick response (QR) codes is now widely found, such as for attendance systems, and validation systems [1], [2]. Incorporating a QR code application with a face detection application is important to produce a system that is able to automatically save faces and read QR codes in the workplace at the same time. This could be the forerunner of a system that can select who can read the QR code. The face detection application uses the OpenCV library which makes it easy to simplify programs related to digital images.

QR code was developed by Denso Corporation, a Japanese company that is mostly engaged in the automotive sector [3]-[5]. QR code is defined as the quick response code, which is a form of changing a barcode from a one-dimensional shape to a two-dimensional shape. There are two types of QR code, i.e.Static QR code and dynamic QR code [6], [7]. Static QR code is that containing information which is not required a specific application to translate the contents. Consequently, the static QR code can be used immediately with the help of the regular QR code reader application [8]. For example, a QR code, if scanned with an ordinary QR code reader application, it contains information that can directly link to a fixed web page [9]. QR code reader consists of 2 types, i.e. static and dynamic. The former is the QR code reader commonly used because the information can be directly understood by the users, while the latter is the QR code reader modified based on the QR code generator because of the required synchronization. Therefore, in the dynamic type, information will bemore secure as it needs synchronization. 
In other words, the information that appears can be directly read by the user. Static QR code is widely used today because the QR code generator application as a QR code generator is available free. Dynamic QR code is the opposite of static QR code, namely QR code which contains information which requires a specific application in translating its contents [10], [11]. The example of using a dynamic QR code is QR-code for https://web.whatsapp.com, when scanned using a regular QR scanner will generally produce an incomprehensible message, because it is an encrypted message from the WhatsApp application [12]. If scanned by using the WhatsApp application, it will do navigation to the WhatsApp web for an account. Therefore, this kind of QR code can only be used by scanning with certain applications.

This type of dynamic QR code is the object of research development, which is added a face detection process [13], [14]. With this face detection, it is expected that it will act as a trigger so that the QR code reader can work [15]. The built system consists of two parts, namely the first part is the generator or QR code generator side and the QR code image scanner (QR code reader).

\section{RESEARCH METHODS}

The method applied in this research is research and development (R\&D), in which there are design, manufacture and system testing phases [16], [17]. Flowchart is used to make it easier for researchers to carry out the stages in research. In general, the flowchart of the research carried out is as shown in Figure 1.

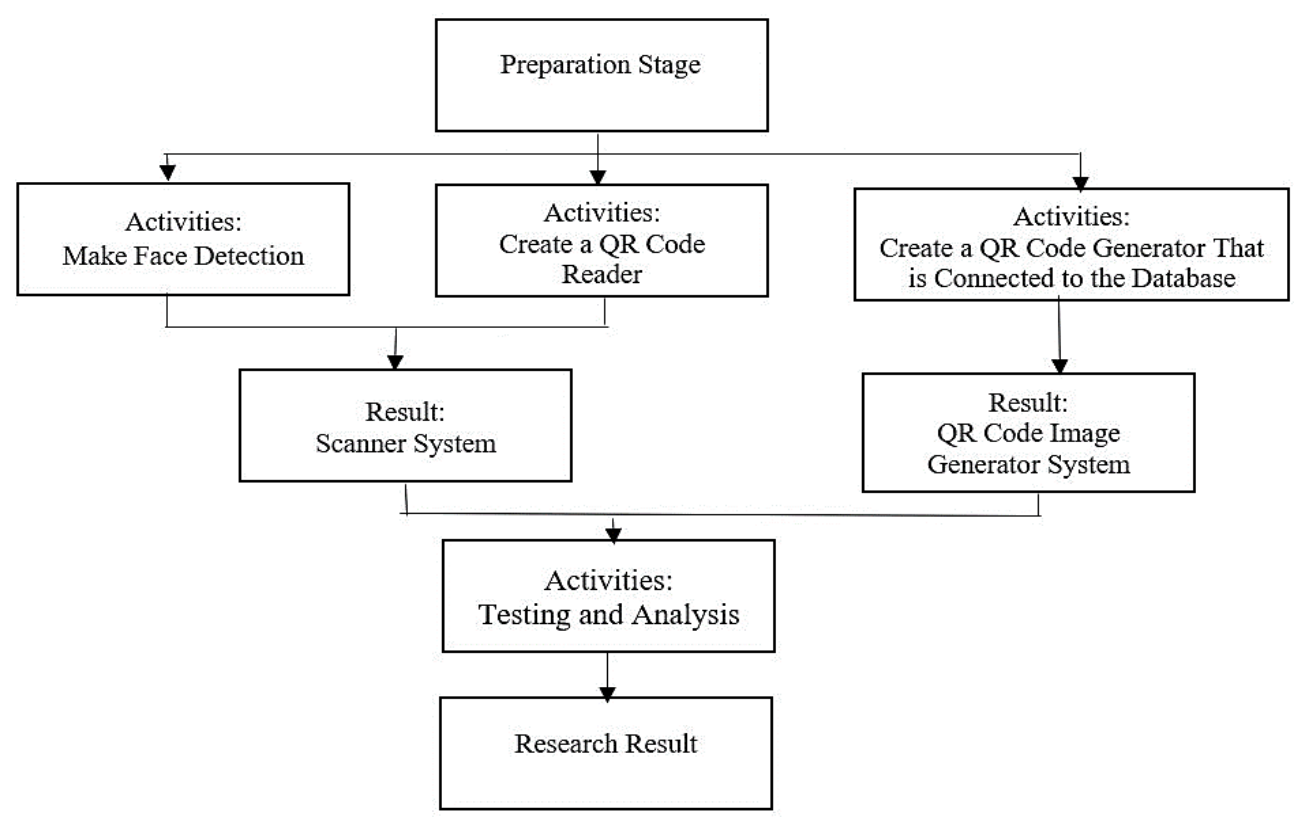

Figure 1. Research flowchart

From Figure 1, the research begins with the preparation stage, i.e., to determine the producing or generating side of the QR code image (QR code Generator) and the scanning side of the QR code image (QR code reader). On the $\mathrm{QR}$ code generator side, a connection to the database is required so that information can be stored, for example to store information on Final Project Student services to replace the original signature in the form of ID, name, Final Project Student service. While the QR code reader requires two webcams and a connection to the same database as the QR code Generator. So as to produce a QR code image maker system and a QR code image scanning system. The test is carried out in a room with light that can still capture normal images by the computer.

\section{MATERIAL AND METHOD}

In this research, supporting materials and methods are needed to be used in the research. In order to support each other, a block diagram is needed. The research begins with creating a system workflow described in a block diagram as shown in Figure 2. 


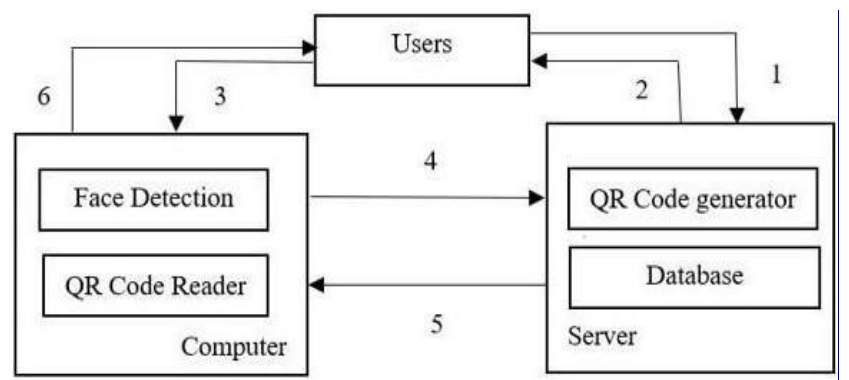

Figure 2. System block diagram

The explanation of Figure 2 is:

- Starting with the user accessing the server to get the QR code generator service (explanation to the arrow 1). Its function is to register information to be saved to a QR code image. Then the user fills in the available fields.

- Then the user notifies the server that the column is completed by pressing the available button. After that the server gives a reply in the form of a QR code image (explanation to the arrow 2).

- The explanation of the direction of arrow number 3, i.e. the QR code image received by the user, the contents of the information can be read if only using a certain scanner (reading device). To use the device, the user and the $\mathrm{QR}$ code image must be simultaneously scanned by the device. The discussion about these scanning devices is in the next section. If the user forces to use the regular QR code reader application to read the contents of the information in the QR code image, encrypted (random) text will appear.

- Then the computer will forward the data from the scanning results to the server (explanation to the arrow 4).

- Then the server responds to the data it receives by sending it to the sending computer (explanation to the arrow 5).

- After that the computer displays the information to the user through a screen based on the data it receives (explanation to the arrow 6).

From Figure 2, hardware and software support is needed so that the research results can be as optimal as possible.

\subsection{Hardware and sofware}

The information inserted in the QR code image is in the form of ID, name, and Final Project Student services. This entry is used to generate QR code images by the QR code generator application later. The next step is how to extract the information. In this study, the required hardware and software are:

a. The intended server is a private server or known as a virtual private server (VPS). This server does not have a real physical form like a computer in general but has services that can be accessed and managed [18]. Besides, every VPS definitely has a public IP. And this VPS can be configured based on its users. In this study applies a VPS with the Linux operating system. After the VPS can be accessed, the next step is to fill in the service in the form of a webserver [19], [20], that is using the Apache application, server scripts using personal home page (PHP) and database applications [21]-[24]. All of these applications are intended to build web-based QR code generator services and database servers. The use of the database here is to store information that will be embedded into a QR code image. In this study, a QR code image will be formed if the users have already completed the data in the form provided and then presses the submit button, which is as shown in Figure 3. Figure 3 is an initial display that must be completed in order that a QR code image can be generated. The filled data will be stored in the database and followed by the process of generating a QR code image as shown in Figure 4. The data stored in the database are intended to be recalled. In this study, in order that data appear automatically, the detected QR code image must be appropriate. The process for generating these images uses the help of the PHP library created by Kentaro Fukuchi and is an opensource library.

b. The intended computer is a computer that is used for the QR code image scanning system and face detection that is on the user's side. Two webcam units are the additional hardware directly connected to the computer. The important specifications on the webcam are that they have autofocus and high definition (HD) resolution of 720p. The goal is that the object captured by this webcam is more focused and sharper, so that the processing program can easily process it. Both webcams use a USB port to connect to a computer. 
c. The intended software is a programming language installed on the computer while the programming language used is the processing language [25], [26]. Processing is an open-source graphics library and integrated development environment (IDE) built for the electronic arts, new media arts, and visual design community with the aim of teaching the fundamentals of computer programming in a visual context. The Processing language uses the Java language, with additional simplifications such as additional classes and mathematical functions and operations. It also provides a graphical user interface to simplify the compile and execution stages. The program for processing $\mathrm{QR}$ codes requires additional program libraries, namely zxing4processing. This library was created by Salvatore Iaconesi and Rolf van Gelder who were released for its development. Moreover, the program for human face detection requires additional program libraries, i.e. opencv processing. This library is open source and includes a face detection algorithm called Haar like feature. Furthermore, this algorithm is supported by the cascade classifier to combine many features [27], [28].

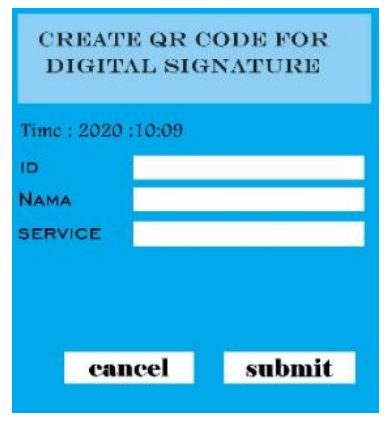

Figure 3. The example of QR code generator service

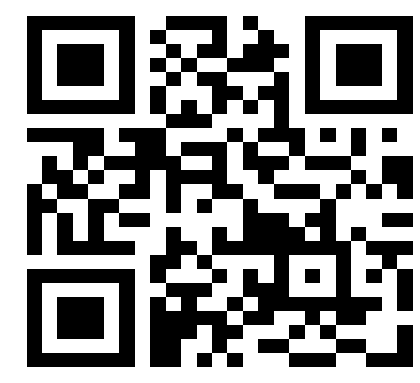

Figure 4. PHP QR code example

\subsection{Data}

There are two types of data taken in this study, i.e. the first is the reading distance by the scanning system (in this case the webcam) with the QR code image object only. The second is the reading distance between the scanner system and the QR code image object and the human face object simultaneously. Data collection is carried out alternately according to the stages.

a. The data retrieving in the first form still uses a webcam unit to scan QR code images in real-time. The data collection procedure is:

- $\quad$ First, make two QR code images through the application in Figure 3.

- After getting the QR code image, make sure the image is saved on the smartphone. In this study, the screen size of the smartphone is 6.4 inches. Then zoom in to the maximum of the QR code image.

- After successfully getting a QR code image as shown in Figure 5, then proceed by testing it to get back the information previously entered through the QR code Generator. With a webcam installed on the computer, then the QR code image is placed on the webcam, the information that appears is shown in Figure 6. And the result will be sililar to in the information entered through the QR code generator as shown in Figure 3.

- Then, carry out the measurement of reading distance in which every change in the reading distance, its QR code image will be changed, resulting in Table 1.

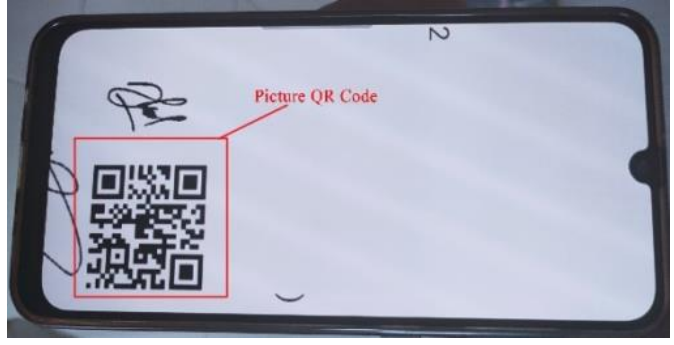

Figure 5. Display of QR code for testing

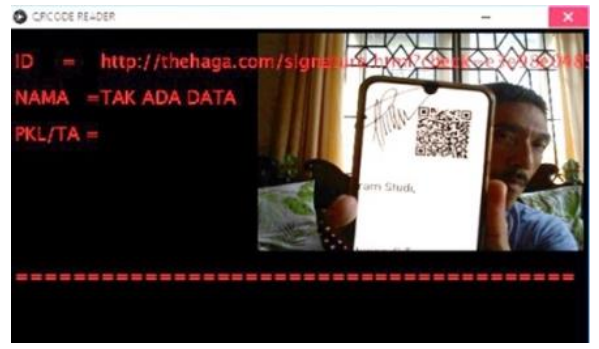

Figure 6. The system display while the expected information appear 
Table 1. Data retrieving with one unit of webcam

\begin{tabular}{ccccccc}
\hline No & Distance $(\mathrm{cm})$ & Test 1 & Test 2 & Test 3 & Test 4 & Test 5 \\
\hline 1 & 1 & 0 & 0 & 0 & 0 & 0 \\
2 & 5 & 0 & 0 & 0 & 0 & 0 \\
3 & 10 & 1 & 0 & 1 & 0 & 1 \\
4 & 15 & 1 & 1 & 1 & 1 & 1 \\
5 & 20 & 1 & 1 & 1 & 1 & 1 \\
6 & 25 & 1 & 1 & 1 & 1 & 1 \\
7 & 30 & 1 & 1 & 1 & 1 & 1 \\
8 & 35 & 1 & 1 & 1 & 1 & 1 \\
9 & 40 & 1 & 1 & 1 & 1 & 1 \\
10 & 45 & 1 & 1 & 1 & 1 & 1 \\
11 & 50 & 1 & 1 & 1 & 1 & 1 \\
12 & 55 & 1 & 1 & 1 & 0 & 1 \\
13 & 60 & 0 & 1 & 1 & 0 & 0 \\
14 & 65 & 0 & 0 & 0 & 0 & 0 \\
15 & 70 & 0 & 0 & 0 & 0 & 0 \\
16 & 75 & 0 & 0 & 0 & 0 & 0
\end{tabular}

b. Data retrieving in the second form uses two webcam units simultaneously, one webcam unit handles QR code images and the other handles human face detection. The data collection procedure is the same as data retrieving with a webcam unit, but there are some additions to the following points:

- $\quad$ The position of the QR code image and the face object faces each webcam, in which the position of the QR code image will be changed by the data, while the position of the user's face does not change (fixed). The position of the face must strictly be put in the green square line on the computer screen; in this case the distance is 1 meter from the face detection webcam. In Figure 7 is a display when the QR code image can provide the expected information. This is indicated by containing the data NAME, SERVICE and ACC TIME. Meanwhile, if the QR code image cannot provide the expected information, the system responds in the form of a sentence with no data.

- Then, the measurement of the reading distance is carried out in which every change in the reading distance, its QR code image will be changed, resulting in Table 2 and Table 3.
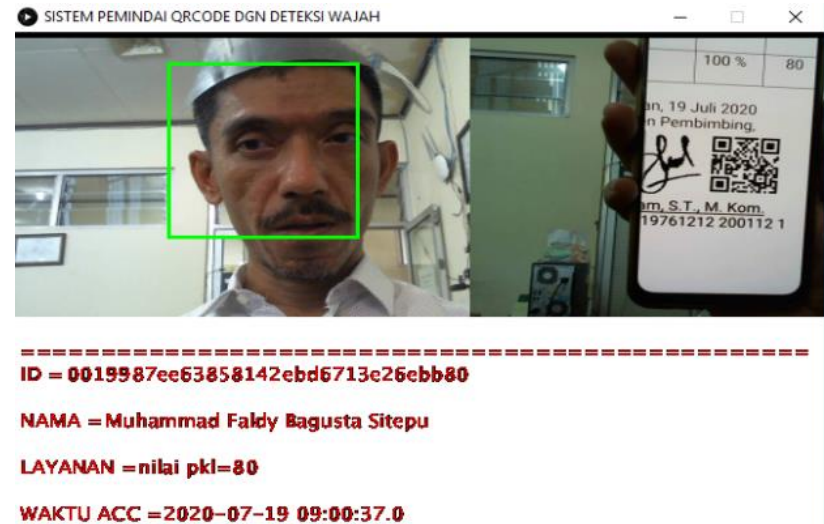

Figure 7. System view when expected information appears

During the experiment or testing, the resulted information is the same information as that entered at the beginning of getting the QR code image. This is because the information stored in the database can be retrieved based on the keywords contained in the image. Vice versa, information will not appear when it does not match. Interestingly, the utilization of QR code as two dimensional have been numerously deliver the benefit for various sectors due to the ability to store large information and extracting them with small amount of little distortion compare to one dimensional barcode [29], [30]. It can be said QR code as a fast readable way that can increase the process to scan, improving the degree of reading up to 360, support for more languages and durability against soil and damage such as several researches conducted for visual cryptography in ciphering messages [31], [32], securing the sharing process of personal confidential information either in term of forgery prevention or anti phishing attack [33]-[37]. In addition, there also several researches that focus on secure recognition process in login system using QR image [38], which mainly have challenges in term of 
localization such as illumination variation and perspective distorting as well as the adaptation into embedded system platform for processing complexity and resource requirement [39]. On the other hand, in term of mobility and agility, the implementation of QR codes support various application such as smart attendance in the university [40] or even in broader level of digital education system [41] and smart city bus for the payment system [42]. Meanwhile, certain technique has been introduced to hide encrypted data using EK-EQR algorithm [43] to improve traceability system [44]. There is also necessity in the further improvement for QR code to protect information with steganography or cryptography in order to guard the knowledge against the attackers [45], which consider the error correction levels up to $30 \%$ [46] to the linkage of multimedia data [47], [48]. Interestingly, mobile computing present a great way to easily apply attendance systems [49] to large and complex battlefield interconnection systems [50], allowing QR codes to work and communicate with users anytime, anywhere and on any device.

Table 2. Data retrieving with two webcams, the detected user's face

\begin{tabular}{ccccccc}
\hline No & $\begin{array}{c}\text { Distsnce } \\
(\mathrm{cm})\end{array}$ & $\begin{array}{c}\text { Test } \\
1\end{array}$ & $\begin{array}{c}\text { Test } \\
2\end{array}$ & $\begin{array}{c}\text { Test } \\
3\end{array}$ & $\begin{array}{c}\text { Test } \\
4\end{array}$ & $\begin{array}{c}\text { Test } \\
5\end{array}$ \\
\hline 1 & 1 & 0 & 0 & 0 & 0 & 0 \\
2 & 5 & 0 & 0 & 0 & 0 & 0 \\
3 & 10 & 0 & 0 & 1 & 1 & 1 \\
4 & 15 & 1 & 1 & 1 & 1 & 1 \\
5 & 20 & 1 & 1 & 1 & 1 & 1 \\
6 & 25 & 1 & 1 & 1 & 1 & 1 \\
7 & 30 & 1 & 1 & 1 & 1 & 1 \\
8 & 35 & 1 & 1 & 1 & 1 & 1 \\
9 & 40 & 1 & 1 & 1 & 1 & 1 \\
10 & 45 & 1 & 1 & 1 & 1 & 1 \\
11 & 50 & 1 & 1 & 1 & 1 & 1 \\
12 & 55 & 1 & 1 & 1 & 0 & 1 \\
13 & 60 & 1 & 1 & 0 & 0 & 0 \\
14 & 65 & 0 & 0 & 0 & 0 & 0 \\
15 & 70 & 0 & 0 & 0 & 0 & 0 \\
16 & 75 & 0 & 0 & 0 & 0 & 0 \\
\hline
\end{tabular}

Table 3. Data retrieving with two webcams, undetected user's face

\begin{tabular}{ccccccc}
\hline No & $\begin{array}{c}\text { Distsnce } \\
(\mathrm{cm})\end{array}$ & $\begin{array}{c}\text { Test } \\
1\end{array}$ & $\begin{array}{c}\text { Test } \\
2\end{array}$ & $\begin{array}{c}\text { Test } \\
3\end{array}$ & $\begin{array}{c}\text { Test } \\
4\end{array}$ & $\begin{array}{c}\text { Test } \\
5\end{array}$ \\
\hline 1 & 1 & 0 & 0 & 0 & 0 & 0 \\
2 & 5 & 0 & 0 & 0 & 0 & 0 \\
3 & 10 & 0 & 0 & 0 & 0 & 0 \\
4 & 15 & 0 & 0 & 0 & 0 & 0 \\
5 & 20 & 0 & 0 & 0 & 0 & 0 \\
6 & 25 & 0 & 0 & 0 & 0 & 0 \\
7 & 30 & 0 & 0 & 0 & 0 & 0 \\
8 & 35 & 0 & 0 & 0 & 0 & 0 \\
9 & 40 & 0 & 0 & 0 & 0 & 0 \\
10 & 45 & 0 & 0 & 0 & 0 & 0 \\
11 & 50 & 0 & 0 & 0 & 0 & 0 \\
12 & 55 & 0 & 0 & 0 & 0 & 0 \\
13 & 60 & 0 & 0 & 0 & 0 & 0 \\
14 & 65 & 0 & 0 & 0 & 0 & 0 \\
15 & 70 & 0 & 0 & 0 & 0 & 0 \\
16 & 75 & 0 & 0 & 0 & 0 & 0 \\
\hline
\end{tabular}

\section{RESULTS AND DISCUSSION}

The discussion begins with getting the parameters contained in Tables 1 to 3:

- Column Distance $(\mathrm{cm})$ is the distance between the QR code image and the webcam in centimeters.

- Column $1^{\text {st }}$ test, $2^{\text {nd }}$ test to $5^{\text {th }}$ test are repeated data collection activities.

- Numbers 0 and 1 describe whether or not is a change in information on the monitor screen. Its function is to find out the response from the webcam whether it can still process (indicated by changes in information data on the monitor screen) or cannot process QR code images (indicated by no change in data at all). For number 1, it means that the information on the screen has changed, while the number 0 means that there is no change in the information on the screen.

Then, in Table 1 there are rows containing non similar numbers, such as those in rows $3,12,13$, while The other rows have similar numbers. So that the non-similar rows will find the approximate value is:

$-\quad$ Row $3=(1+0+1+0+1) / 5=3 / 5=0.6$ and becomes 1 .

- $\quad$ Row $12=(1+1+1+0+1) / 5=4 / 5=0.8$ and becomes 1 .

- $\quad$ Row $13=(0+1+1+0+0) / 5=2 / 5=0.4$ and becomes 0 .

From the calculation of this approach, the condition in Table 1 is:

- The distance at $10 \mathrm{~cm}$ has changes in information.

- The distance at $55 \mathrm{~cm}$ has changes in information.

- The distance at $60 \mathrm{~cm}$ has no change in information.

Then in Table 2 there are rows containing non-similar numbers, such as rows 3,12 , 13., while the other rows have similar numbers. So that the non-similar rows will find the approximate value is:

- $\quad$ Row $3=(0+0+1+1+1) / 5=3 / 5=0.6$ and becomes 1

- $\quad$ Row $12=(1+1+1+0+1) / 5=4 / 5=0.8$ and becomes 1

$-\quad$ Row $13=(1+1+0+0+0) / 5=2 / 5=0.4$ and becomes 0

From the calculation of this approach, the condition in Table 2 is:

- The distance at $10 \mathrm{~cm}$ has changes in information.

- The distance at $55 \mathrm{~cm}$ has changes in information.

- The distance at $60 \mathrm{~cm}$ has no change in information. 
Continued in Table 3, all rows contain the number 0 which means there is no change or the system does not respond. Therefore, they can be summarized into the following Tables 4 and 5:

Table 4. The results of the conclusion Table 1

\begin{tabular}{ccc}
\hline No & Distance $(\mathrm{cm})$ & Status \\
\hline 1 & 1 & Unchange \\
2 & 5 & Unchange \\
3 & 10 & Change \\
4 & 15 & Change \\
5 & 20 & Change \\
6 & 25 & Change \\
7 & 30 & Change \\
8 & 35 & Change \\
9 & 40 & Change \\
10 & 45 & Change \\
11 & 50 & Change \\
12 & 55 & Change \\
13 & 60 & Unchange \\
14 & 65 & Unchange \\
15 & 70 & Unchange \\
16 & 75 & Unchange \\
\hline
\end{tabular}

Table 5. The results of the conclusion Table 2

\begin{tabular}{ccc}
\hline No & Distance $(\mathrm{cm})$ & Status \\
\hline 1 & 1 & Unchange \\
2 & 5 & Unchange \\
3 & 10 & Change \\
4 & 15 & Change \\
5 & 20 & Change \\
6 & 25 & Change \\
7 & 30 & Change \\
8 & 35 & Change \\
9 & 40 & Change \\
10 & 45 & Change \\
11 & 50 & Change \\
12 & 55 & Change \\
13 & 60 & Unchange \\
14 & 65 & Unchange \\
15 & 70 & Unchange \\
16 & 75 & Unchange \\
\hline
\end{tabular}

\section{CONCLUSION}

In summary, perform face detection using a $\mathrm{QR}$ code as a face identifier that accesses the QR code so that it gets a track record. The success of reading the QR code is influenced by 2 factors, namely the first is the distance between the QR code object and the webcam and the second is detecting the user's face. With multicam, these two factors can work simultaneously, because each camera handles each process. Without these two factors, the system will not work optimally. In addition, the QR code reader ( $\mathrm{QR}$ code reader) and QR code generator (QR code Generator) cannot be used without a VPS. This is because every transaction can be stored/recorded in it, in the form of the user's face and information. Besides, the dynamic type of QR code reader applied in this study requires a QR code generator for synchronizing information, so that the information cannot be directly understood by users when using any QR code reader device on the market. With the ability to detect the user's face and store it, it is hoped that in the next research the system can secure the information contained in the QRCode based on the user's face through face recognition.

\section{REFERENCES}

[1] A. Abas, Y. Yusof, R. Din, F. Azali, and B. Osman, "Increasing data storage of coloured QR code using compress, multiplexing and multilayered technique," Bull. Electr. Eng. Informatics, vol. 9, no. 6, pp. 2555-2561, 2020, doi: 10.11591/eei.v9i6.2481.

[2] P. Satanasaowapak, W. Kawseewai, S. Promlee, and A. Vilamat, "Residential access control system using QR code and the IoT," Int. J. Electr. Comput. Eng., vol. 11, no. 4, pp. 3267-3274, 2021, doi: 10.11591/ijece.v11i4.pp3267-3274.

[3] F. Kumagai, "What Can Be Done Before a Municipality “Disappears": Making the Best of Negative Municipal Resources," in Municipal Power and Population Decline in Japan: Goki-Shichido and Regional Variations, Singapore: Springer Singapore, 2020, pp. 229-264.

[4] S. C. Cha, H. Wang, Z. Tan, Y. J. Joung, Y. C. Tseng, and K. H. Yeh, "On Privacy Aware Carriers for Value-Possessed e-Invoices Considering Intelligence Mining," IEEE Trans. Emerg. Top. Comput. Intell., vol. 4, no. 5, pp. 641-652, 2020, doi: 10.1109/TETCI.2019.2938547.

[5] M. Xu et al., "Stylized Aesthetic QR code," IEEE Trans. Multimed., vol. 21, no. 8, pp. 1960-1970, 2019, doi: 10.1109/TMM.2019.2891420.

[6] S. Li, J. Shang, Z. Duan, and J. Huang, "Fast detection method of quick response code based on run-length coding," IET Image Process., vol. 12, no. 4, pp. 546-551(5), Apr. 2018, [Online]. Available: https://digitallibrary.theiet.org/content/journals/10.1049/iet-ipr.2017.0677.

[7] U. A. Waqas, M. Khan, and S. I. Batool, "A new watermarking scheme based on Daubechies wavelet and chaotic map for quick response code images,” Multimed. Tools Appl., vol. 79, no. 9, pp. 6891-6914, 2020, doi: 10.1007/s11042-019-08570-5.

[8] E. Ozan, "QR code Based Signage to Support Automated Driving Systems on Rural Area Roads," in Industrial Engineering and Operations Management II, 2019, pp. 109-116.

[9] M. Abdolahi, H. Jiang, and B. Kaminska, "Structural colour $\{Q R\}$ codes for multichannel information storage with enhanced optical security and life expectancy," Nanotechnology, vol. 30, no. 40, p. 405301, Jul. 2019, doi: 10.1088/1361-6528/ab2d3b.

[10] I. Farida, F. R. Agung, R. Aisyah, and D. Nasrudin, "Learning crude oil based on enviromental literacy," J. Phys. Conf. Ser., vol. 1563, no. 1, 2020, doi: 10.1088/1742-6596/1563/1/012047.

[11] R. Focardi, F. L. Luccio, and H. A. M. Wahsheh, "Usable security for QR code," J. Inf. Secur. Appl., vol. 48, p. 102369, 2019, doi: https://doi.org/10.1016/j.jisa.2019.102369.

[12] J. Jabbar, S. I. Malik, G. AlFarsi, and R. M. Tawafak, "The Impact of WhatsApp on Employees in Higher Education," in Recent Advances in Intelligent Systems and Smart Applications, M. Al-Emran, K. Shaalan, and A. E. Hassanien, Eds. Cham: Springer International Publishing, 2021, pp. 639-651.

[13] W. Liu, B. Wang, Y. Li, and M. Wu, "Screen-camera communication system based on dynamic QR code," IOP Conf. Ser. Mater. Sci. Eng., vol. 790, no. 1, 2020, doi: 10.1088/1757-899X/790/1/012012. 
[14] H. Baidong and Z. Yukun, "Research on Quickpass Payment Terminal Application System Based on dynamic QR code," J. Phys. Conf. Ser., vol. 1168, no. 3, 2019, doi: 10.1088/1742-6596/1168/3/032059.

[15] A. R. Jones, M. D. Aspinall, and M. J. Joyce, "A remotely triggered fast neutron detection instrument based on a plastic organic scintillator," Rev. Sci. Instrum., vol. 89, no. 2, p. 23115, 2018, doi: 10.1063/1.5012121.

[16] J. Choi and F. J. Contractor, "Improving the Progress of Research \& Development (R\&D) Projects by Selecting an Optimal Alliance Structure and Partner Type," Br. J. Manag., vol. 30, no. 4, pp. 791-809, 2019, doi: 10.1111/1467-8551.12267.

[17] K. Lee, Y. Jeong, and B. Yoon, "Developing an research and development (R\&D) process improvement system to simulate the performance of R\&D activities," Comput. Ind., vol. 92-93, pp. 178-193, 2017, doi: https://doi.org/10.1016/j.compind.2017.08.001.

[18] H. A. Adam, Julham, A. R. Lubis, F. Fachrizal, and Y. Fatmi, "Design information seating chart system in classroom with wireless sensor network," in Journal of Physics: Conference Series, 2019, vol. 1361, no. 1, doi: 10.1088/1742-6596/1361/1/012007.

[19] T. Fadhilah Iskandar, M. Lubis, T. Fabrianti Kusumasari, and A. Ridho Lubis, "Comparison between client-side and server-side rendering in the web development," IOP Conf. Ser. Mater. Sci. Eng., vol. 801, no. 1, 2020, doi: 10.1088/1757-899X/801/1/012136.

[20] I. Kamil, Julham, M. Lubis, and A. R. Lubis, "Management maintenance system for remote control based on microcontroller and virtual private serve," Indones. J. Electr. Eng. Comput. Sci., vol. 16, no. 3, 2019, doi: 10.11591/ijeecs.v16.i3.pp1349-1355.

[21] A. R. Lubis, F. Fachrizal, and H. Maulana, "Database management optimization using PostgreSQL replication database in database system," Adv. Sci. Lett., vol. 23, no. 5, 2017, doi: 10.1166/asl.2017.8286.

[22] Y. Y. Lase, Haryadi, and Y. Fatmi, "Analysis of effective storage time to deteremine the quality of milk usingsimple additive weighting method,” J. Phys. Conf. Ser., vol. 1361, no. 1, 2019, doi: 10.1088/1742-6596/1361/1/012077.

[23] A. Ramadhan, M. Lubis, W. Puspitasari, and A. R. Lubis, "Development of Web Stock Opname Application With SAP Business One Using Scrum Method," in 2019 International Conference of Computer Science and Information Technology (ICoSNIKOM), Nov. 2019, pp. 1-5, doi: 10.1109/ICoSNIKOM48755.2019.9111526.

[24] A. R. Lubis, M. K. M. Nasution, O. S. Sitompul, and E. M. Zamzami, “A Framework of Utilizing Big Data of Social Media to Find Out the Habits of Users Using Keyword," 2020, pp. 140-144.

[25] A. R. Lubis et al., "Obtaining Value From The Constraints in Finding User Habitual Words,” pp. 8-11, 2020.

[26] A. R. Lubis, M. K. M. Nasution, O. Salim Sitompul, and E. Muisa Zamzami, "The effect of the TF-IDF algorithm in times series in forecasting word on social media," Indones. J. Electr. Eng. Comput. Sci., vol. 22, no. 2, p. 976, 2021, doi: 10.11591/ijeecs.v22.i2.pp976-984.

[27] M. Almasi, "An Investigation on Face Detection Applications," Int. J. Comput. Appl., vol. 177, no. 21, pp. 17-23, 2019, doi: 10.5120/ijca2019919664.

[28] V. G. Patel and A. Suthar, "Human Face Detection and Tracking," Int. J. Comput. Eng. Technol., vol. 9, no. 4, pp. 187-195, 2018, doi: 10.13140/RG.2.2.24467.43042.

[29] S. Singh, “QR code Analysis,” Int. J. Adv. Res. Comput. Sci. Softw. Eng., vol. 6, no. 5, pp. 89-92, 2016, [Online]. Available: www.ijarcsse.com.

[30] S. Nasir, S. Al-Qaraawi, and M. Croock, "Design and implementation a network mobile application for plants shopping center using QR code," Int. J. Electr. Comput. Eng., vol. 10, no. 6, pp. 5940-5950, 2020, doi: 10.11591/ijece.v10i6.pp5940-5950.

[31] S. K. Thamer and B. N. Ameen, “A new method for ciphering a message using QR code,” Comput. Sci. Eng., vol. 6, no. 2, pp. 1924, 2016, doi: 10.5923/j.computer.20160602.01.

[32] X. Cao, L. Feng, P. Cao, and J. Hu, "Secure QR code Scheme Based on Visual Cryptography," vol. 133, pp. 433-436, 2016, doi: 10.2991/aiie-16.2016.99.

[33] M. S. Ahamed and H. Asiful Mustafa, "A Secure QR code System for Sharing Personal Confidential Information," 5th Int. Conf. Comput. Commun. Chem. Mater. Electron. Eng. IC4ME2 2019, pp. 11-12, 2019, doi: 10.1109/IC4ME247184.2019.9036521.

[34] A. T. Purnomo, Y. S. Gondokaryono, and C. S. Kim, "Mutual authentication in securing mobile payment system using encrypted QR code based on public key infrastructure," Proc. 2016 6th Int. Conf. Syst. Eng. Technol. ICSET 2016, pp. 194-198, 2017, doi: 10.1109/FIT.2016.7857564

[35] V. Mavroeidis and M. Nicho, "Quick response code secure: A cryptographically secure anti-phishing tool for QR code attacks," Lect. Notes Comput. Sci. (including Subser. Lect. Notes Artif. Intell. Lect. Notes Bioinformatics), vol. 10446 LNCS, no. August 2017, pp. 313-324, 2017, doi: 10.1007/978-3-319-65127-9_25.

[36] A. R. Lubis, F. Fachrizal, M. Lubis, and H. M. Tahir, "Wireless service at Public University: A survey of users perception on security aspects," in 2018 International Conference on Information and Communications Technology, ICOIACT 2018, 2018, vol. 2018-Janua, doi: 10.1109/ICOIACT.2018.8350786.

[37] Julham, F. Fachrizal, H. A. Adam, Y. Fatmi, and A. R. Lubis, "Security of data communications between embedded arduino system s with substitution encryption," in Proceedings of the 2nd International Conference on Informatics and Computing, ICIC 2017, 2018, vol. 2018-Janua, doi: 10.1109/IAC.2017.8280578.

[38] S. Dutta, S. Singh, and P. Ghodke, "Secure Login System Using QR-Image,” Int. J. Comput. Appl. Technol. Res., vol. 8, no. 1, pp. 1-3, 2019, doi: 10.7753/ijcatr0801.1001.

[39] H. Tribak and Y. Zaz, "QR code Recognition based on Principal Components Analysis Method," Int. J. Adv. Comput. Sci. Appl., vol. 8, no. 4, pp. 241-248, 2017, doi: 10.14569/ijacsa.2017.080433.

[40] F. Masalha and N. Hirzallah, “A Students Attendance System Using QR code,” Int. J. Adv. Comput. Sci. Appl., vol. 5, no. 3, pp. 75-79, 2014, [Online]. Available: http://bvs.sld.cu/revistas/mciego/vol14_supl2_08/articulos/a6_v14_supl208.htm.

[41] S. Goyal, S. Yadav, and M. Mathuria, "Exploring concept of QR code and its benefits in digital education system," 2016 Int. Conf. Adv. Comput. Commun. Informatics, ICACCI 2016, pp. 1141-1147, 2016, doi: 10.1109/ICACCI.2016.7732198.

[42] S. L. Fong, D. Wui Yung Chin, R. A. Abbas, A. Jamal, and F. Y. H. Ahmed, "Smart City Bus Application with QR code: A Review," 2019 IEEE Int. Conf. Autom. Control Intell. Syst. I2CACIS 2019 - Proc., no. June, pp. 34-39, 2019, doi: 10.1109/I2CACIS.2019.8825047.

[43] N. Naik, N. Kadam, and M. Bhalekar, "Technique to Hide Encrypted Data in QR codes using EK-EQR Algorithm," Int. J. Comput. Appl., vol. 161, no. 12, pp. 25-28, 2017, doi: 10.5120/ijca2017913397.

[44] L. Tarjan, I. Šenk, S. Tegeltija, S. Stankovski, and G. Ostojic, "A readability analysis for QR code application in a traceability system," Comput. Electron. Agric., vol. 109, pp. 1-11, 2014, doi: 10.1016/j.compag.2014.08.015.

[45] M. Alajmi, I. Elashry, H. S. El-Sayed, and O. S. Farag Allah, "Steganography of Encrypted Messages Inside Valid QR codes," IEEE Access, vol. 8, pp. 27861-27873, 2020, doi: 10.1109/ACCESS.2020.2971984.

[46] A. Mishra and M. Mathuria, "A Review on QR code," Int. J. Comput. Appl., vol. 164, no. 9, pp. 17-19, 2017, doi: 10.5120/ijca2017913739.

[47] M. Z. Alksasbeh, B. A. Y. Alqaralleh, T. Abukhalil, A. Abukaraki, T. Al Rawashdeh, and M. Al-Jaafreh, "Smart detection of offensive words in social media using the soundex algorithm and permuterm index," Int. J. Electr. Comput. Eng., vol. 11, no. 5, pp.

Int J Artif Intell, Vol. 11, No. 1, March 2022: 327-335 
4431-4438, 2021, doi: 10.11591/ijece.v11i5.pp4431-4438

[48] C. L. Li, Y. Su, and R. Z. Wang, "Generating photomosaics with QR code capability," Mathematics, vol. 8, no. 9, 2020, doi: 10.3390/math8091613.

[49] F. Zailani and A. A. Shamsu Adli, "QR code Attendance System," 2020.

[50] M. Guha and J. C. Calliott, "Interpreting the Signs The Prospects of QR Coding the Battlespace," Journalof Indo-Pacific Aff., pp. 201-235, 2021.

\section{BIOGRAPHIES OF AUTHORS}

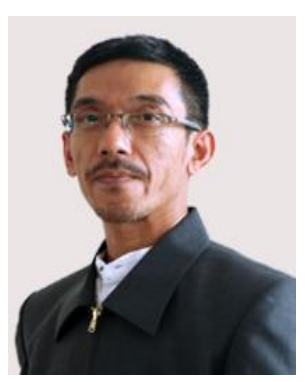

Julham, ST., M.Kom. (iD 8d SC P holds a master from Universitas Putra Indonesia Yptk Padang in 2008. He is currently an associate professor at Department of Computer Engineering and Informatics, Politeknik Negeri Medan, Indonesia. His research includes computer networking, embedded system, computer vision, artificial intelligence. He can be contacted at email: julham@polmed.ac.id

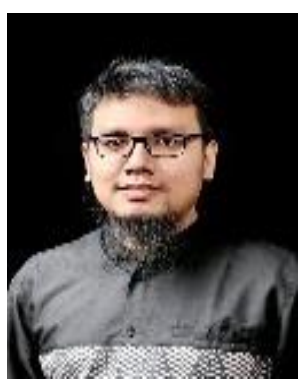

Muharman Lubis, Ph.D. IT. (D) SC S Sas finished his Doctoral degree recently in Information Technology at 2017 in International Islamic University Malaysia, he also received his Master degree from same university at 2011 and Bachelor degree from University Utara Malaysia at 2008, both in Information Technology. He joined as a Lecturer in the School of Industrial Engineering, Telkom University, in 2017. His research interests include privacy protection, information security awareness, knowledge management and project management. He can be contacted at email: muharmanlubis@telkomuniversity.ac.id

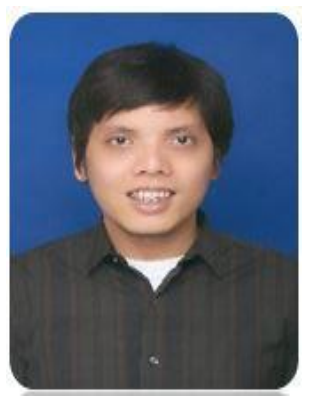

Arif Ridho Lubis, M.Sc. IT. (iD) SC P he got master from University Utara Malysia in 2012 and graduate from University Utara Malaysia in 2011, both information technology. He is a lecturer in Department of Computer Engineering and Informatics, Politeknik Negeri Medan in 2015. His research interest includes computer science, network, science and project management. He can be contacted at email: arifridho@polmed.ac.id

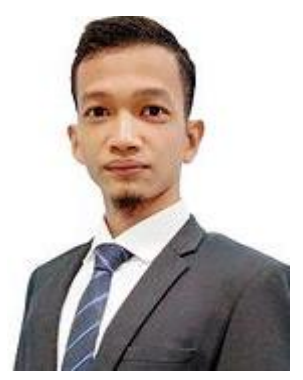

Al-Khowarizmi, M.Kom. (D) SC P was born in Medan, Indonesia, in 1992. He is a lecturer in Department of Information Technology-Faculty of Computer Science and Information Technology at Universitas Muhammadiyah Sumatera. He got master from University of Sumatera Utara in 2017 and graduate from Universitas Harapan Medan in 2014, both information system. His main research interest is data science, big data, machine learning, neural network, artificial intelligence and business intelligence. He can be contacted at email: alkhowarizmi@umsu.ac.id

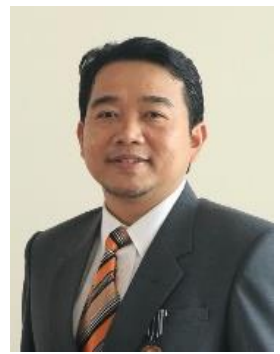

Idham Kamil, S.T., M.T. (D) $8 \mathrm{SC}$ ( $\mathrm{P}$ he obtained his master's degree from Universitas Sumatera Utara in 2007 and graduated from Universitas Sumatera Utara in 1996, both in Mechanical engineering. He is a lecturer at the Department of Mechanical Engineering at the Medan State Polytechnic. His research interests include management maintenance, renewable energy, and Networking. He can be contacted at email: idhamkamil@ polmed.ac.id 